\title{
MECHANICAL PROPERTIES OF COMPOSITES REINFORCED WITH TECHNICAL EMBROIDERY MADE OF FLAX FIBERS
}

\author{
Agata Poniecka ${ }^{1}$, Marcin Barburski ${ }^{1, *}$, Mariusz Urbaniak ${ }^{2}$ \\ 1 Lodz University of Technology, Faculty of Material Technologies and Textile Design, Institute of Architecture of Textiles, Zeromskiego 116 , \\ Lodz 90-924, Poland \\ 2 Lodz University of Technology, Faculty of Mechanical Engineering, Department of Strength of Materials, Zeromskiego 116, Lodz 90-924, Poland \\ *Corresponding author: E-mail: marcin.barburski@p.lodz.pl
}

\begin{abstract}
:
The main purpose of the article is to present the new possibilities of producing composite reinforcement with the use of a computer embroidery machine. This kind of production is in line with the principles of sustainable development. The study below presents the results of strength tests of composites containing sevenfold embroidery systems. Each variant included different directions of arrangement of individual layers as a reinforcement. Flax roving was used to strengthen the composite. Flax fibers are characterized by the highest strength among all-natural fibers, at the level of 50-80 cN/tex. The composite was made using the vacuum bag method, using epoxy resin. The embroidery was made on a ZSK embroidery machine, type JCZA 0109-550. The test material was subjected to strength tests-tensile strength, tensile elongation, and bending strength, on the INSTRON machine. Based on the research, it can be concluded that the arrangement of the roving in the direction of the tensile force allowed to obtain the best mechanical properties.
\end{abstract}

\section{Keywords:}

Technical embroidery; embroidery; embroidery machine; automated fiber placement; lay-up; composite; vacuum infusion; flax fibers; particle-reinforcement

\section{Introduction}

Embroidery is primarily associated with the traditional art of decorating textiles with a needle and a thread or a yarn. Traces of its use can be found in almost every culture, and it has its origins in ancient times. Initially, it can be assigned with a utilitarian function (sewing and repairing clothes), then a decorative one, in the 19th century, it rose to the rank of art, and as a part of the industrial revolution, it entered the mass production [1].

Currently, embroidery has many functional technical applications. It can be, for example, used to reinforce composites. This is a completely new field of industry that is not yet very popular. Embroidery is mainly used to attach wires, but there are no scientific publications dealing with the use of embroidery as reinforcement of the composite. The biggest advantage of this solution is the ability to make a precisely planned shape without producing waste.

Composites reinforced with natural fibers (Fiber Reinforced Plastics, FRP) are characterized by high stiffness, strength, tolerance to fatigue damage, low coefficient of thermal expansion, low corrosion, high internal damping, and low operating costs. In addition, they are durable, renewable, biodegradable, and more cost-effective to manufacture compared to synthetic fiber composites. Due to the low density and cell structure of natural fibers, these composites have very good acoustic and thermal insulation properties. Natural fibers are especially recommended in cases where it is important to reduce production costs and where it can compete with artificial glass fibers (E-glass fiber), where high stiffness per unit mass is desired [2-7].

Most often, composites are made of two phases-fiber and matrix. The properties of the composite obtained are higher than the properties of the individual phases separately-i.e., fibers and matrix. Two phases create a new material, with better properties. In the case of the presented research, flax roving and epoxy resin were used. The fibers contained in the composite are used to transfer internal loads, while the matrix is a continuous phase that is used to bind and transfer loads to the fibers $[8,9]$. Flax has the highest strength among the natural fibers. Additionally, the cultivation of flax is more environmentally friendly than the production of chemical fibers. The main disadvantage of flax fibers is high hygroscopicity; however, flax exhibits increased wet strength compared to the dry state [10-13].

The production of the composite allows for conscious shaping of construction and operational indicators. Fabrics and knitted fabrics are anisotropic in nature; therefore, when used for 
the production of composites in the form of laminates, it is impossible to diversify the reinforcement phase. On the other hand, embroidery allows for spatial changes in the content and orientation of the fibers. Thanks to this, when designing the embroidery, it is possible to take into account changes that increase the resistance to the acting forces [14]. One of the techniques that makes it possible to produce the research object is the Tailored Fiber Placement (TFP) technology. It consists of placing the textile material in an appropriate, preprogrammed place [15]. In the case of the tests presented below, it is done with a computer embroidery machine. The use of TFP technology allows for local strengthening of the manufactured product and to reduce material losses to a minimum.

Locally reinforced composites can be used where it is not necessary to transfer loads over the entire surface of the composite, but only on its selected fragments, e.g. beams, ribs, stiffeners in the form of a grid. The use of TFP technology also allows the production of composites with complex shapes, making it possible to omit the stage of cutting out the material [16]. It is a process that allows the creation of three-dimensional light structures and the placement of threads (fibers, yarns) on the base material in any direction. The use of embroidery in the industry is an extremely dynamic field. Technical embroidery is used in many fields of industry, mainly in broadly understood engineering, medicine, or in intelligent textiles. Embroidered reinforcement structures are used in construction, automotive, and space engineering. A specific feature of such composite reinforcements is their anisotropic properties due to the significant influence of the fiber orientation on the stresses in the elements. For medical applications, embroidery is used in the production of textiles (e.g. dressings) and tissue engineering. However, it is most often used in the field of intelligent textiles [17]. It is used, for example, to attach wireless, textile antennas and sensors to items of clothing [18]. Thanks to repeatability, high efficiency of embroidery machines, and customized

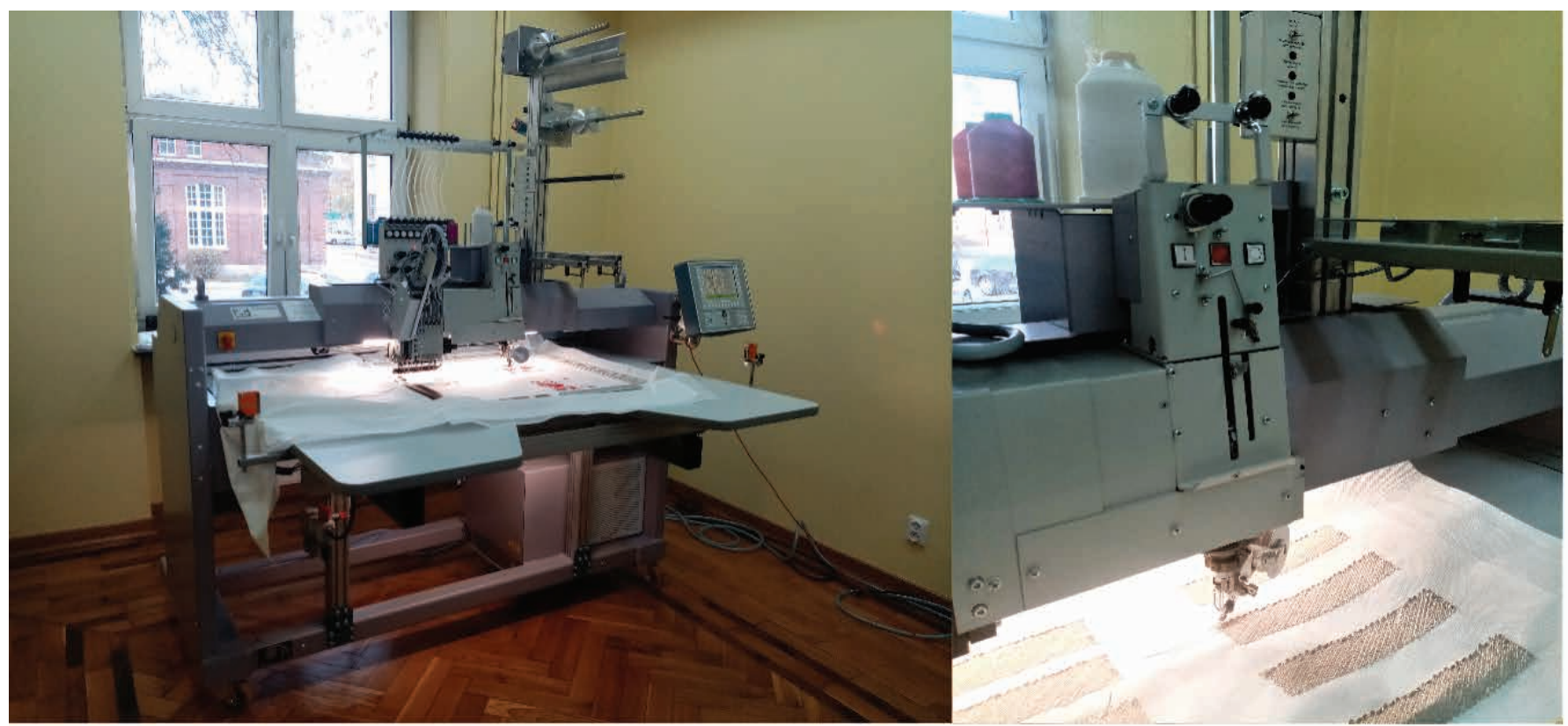

designs, embroidery is one of the most advanced ways to integrate electronics with textile basis [19].

The main purpose of this work is to show that embroidered reinforcements can successfully replace the existing solutions, i.e. the use of flat textile products as reinforcement for composites. The most important advantage of using embroidered reinforcements is reducing the consumption of materials, and thus reducing the amount of waste generated. The whole idea fits into the issue of sustainable development, which is now becoming a very important element of industry.

\section{Experimental}

\subsection{Materials}

The embroidery was made on a computerized embroidery machine made by ZSK, type JCZA 0109-550. This embroidery machine is equipped with a W-type head, which allows the selected medium (in this case, flax roving) to be placed on a textile backing or other type of material in the $x$ - and $y$-axis system. These mediums are attached to the backing with a zigzag stitch with the use of fastening yarns.

Embroidery variants were designed in a program specially dedicated to these embroiderers machines-GiS BasePack, version 10.

Figure 1 presents a computerized embroidery machine and its component-the W-head for technical embroidery.

The case of studies were polymer composites containing seven-layer systems of technical embroidery as reinforcement. The embroidery was made of flax roving with a linear mass of 360 tex and polyamide monofilament with a linear mass of 11 tex. Roving was purchased from Safilin, and monofilament from Gunold. The roving is laid flat and fastened with a zig-zag

Figure 1. ZSK computer embroidery machine type JCZA 0109-550 with a W-type head for technical embroidery (own source). 
stitch to the fabric with fleece. The length of the zig-zag stitch was $2 \mathrm{~mm}$ and the width was $1.2 \mathrm{~mm}$. The tensile strength of the flax roving was $7.37 \mathrm{cN} / \mathrm{tex}$ and the tensile elongation was $1.69 \%$. The backing was cotton fabric with a surface weight of $280 \mathrm{~g} / \mathrm{m}^{2}$ and a polyester fleece with a surface weight of $35 \mathrm{~g} /$ $\mathrm{m}^{2}$. The fabric was purchased from Modeo and fleece form Haftix. Each sample consisted sequentially of fleece, fabric, and seven layers of embroidery.

Six variants of research samples were produced. Each variant was made out of seven layers with a different arrangement of the roving. The individual variants differed in the direction of the roving arrangement in individual layers in relation to the longitudinal direction of the sample. Placement angles used were $0^{\circ}, 45^{\circ}, 90^{\circ}$, and $-45^{\circ}$. The arrangement of the roving in individual layers is shown in Figures 2-5.

The detailed arrangement of layers in individual variants is presented in Table 1.

After that, embroideries were laminated with epoxy resin and made composites using the vacuum bag method. The epoxy system was used to produce composite samples are HAVEL Composites LH145 epoxy resin and HAVEL Composites H135 hardener in the ratio 100:35. The properties of the resin are given in Table 2.

This method consists of manually filtering the composite layers with a resin mixture, tightly closing the entire package on the mold in a highly flexible vacuum bag, and then removing unnecessary air along with any excess resin mixture using a vacuum pump. Any excess resin mixture is removed by suction into the resin trap. Subsequent layers applied to the embroidery, used for the proper implementation of the composite, are perforated separating foil, glass fabric, and permeable-absorbent nonwoven fabric.

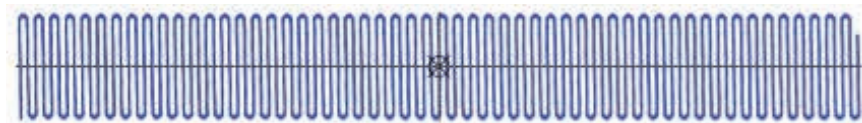

Figure 2. The arrangement of the roving at an angle of $0^{\circ}$ to the longitudinal direction of the sample (own source).

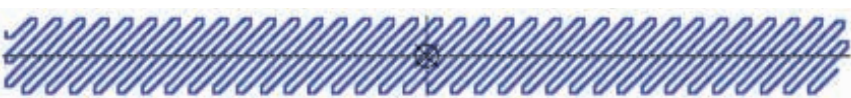

Figure 3. The arrangement of the roving at an angle of $90^{\circ}$ to the longitudinal direction of the sample (own source).

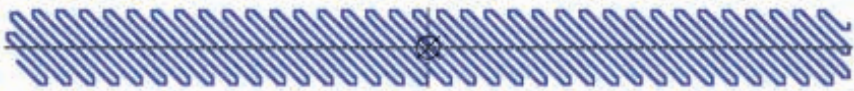

Figure 4. The arrangement of the roving at an angle of $45^{\circ}$ to the longitudinal direction of the sample (own source).

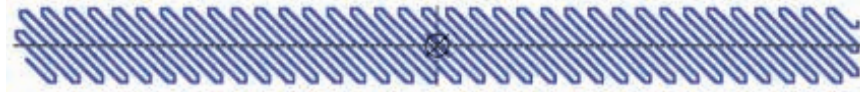

Figure 5. The arrangement of the roving at an angle of $-45^{\circ}$ to the longitudinal direction of the sample (own source).
Table 1. The direction of placing the roving in successive layers of individual variants

\begin{tabular}{|c|c|}
\hline $\begin{array}{c}\text { Variant } \\
\text { number }\end{array}$ & $\begin{array}{c}\text { The direction of the roving in the } \\
\text { successive layers of the embroidery }\end{array}$ \\
\hline 1 & $0^{\circ}, 45^{\circ},-45^{\circ}, 90^{\circ},-45^{\circ}, 45^{\circ}, 0^{\circ}$ \\
\hline 2 & $90^{\circ}, 45^{\circ},-45^{\circ}, 0^{\circ},-45^{\circ}, 45^{\circ}, 90^{\circ}$ \\
\hline 3 & $0^{\circ}, 90^{\circ}, 0^{\circ}, 90^{\circ}, 0^{\circ}, 90^{\circ}, 0^{\circ}$ \\
\hline 4 & $0^{\circ}, 45^{\circ}, 0^{\circ},-45^{\circ}, 0^{\circ}, 45^{\circ}, 0^{\circ}$ \\
\hline 5 & $90^{\circ}, 45^{\circ}, 90^{\circ},-45^{\circ}, 90^{\circ}, 45^{\circ}, 90^{\circ}$ \\
\hline 6 & $0^{\circ}, 0^{\circ}, 0^{\circ}, 0^{\circ}, 0^{\circ}, 0^{\circ}, 0^{\circ}$ \\
\hline
\end{tabular}

Table 2. Properties of the resin used to make the composite

\begin{tabular}{|c|c|}
\hline Properties & Value \\
\hline Density of liquid form & $1.15 \mathrm{~kg} / \mathrm{l}$ \\
\hline Gel time & $4 \mathrm{~h}$ \\
\hline \multicolumn{2}{|c|}{ Properties of cured resin } \\
\hline Total volume shrinkage & $1-2 \%$ \\
\hline Heat deflection temperature & $65^{\circ} \mathrm{C}$ \\
\hline \multicolumn{2}{|c|}{ Mechanical properties of cured resin } \\
\hline Flexural strength & $100 \mathrm{~N} / \mathrm{mm}^{2}$ \\
\hline Flexural modulus & $2.8-3.0 \mathrm{kN} / \mathrm{mm}^{2}$ \\
\hline Elongation at break & $4.5-5.0 \%$ \\
\hline Tensile strength & $60-70 \mathrm{~N} / \mathrm{mm}^{2}$ \\
\hline
\end{tabular}

During the curing of the composite, the pressure inside the vacuum bag is maintained at $70-80 \mathrm{kPa}$. The hardening time is about $4 \mathrm{~h}$, depending on the components of the resin mixture used and the temperature. The curing temperature was $25^{\circ} \mathrm{C}$.

The construction of composites is based on at least two phases, one of them is the reinforcing phase-in this case, it was the seven-layer embroidery system. The use of the vacuum bag method allowed for a satisfactory, but not maximum, elimination of disturbances in the structure of the composite.

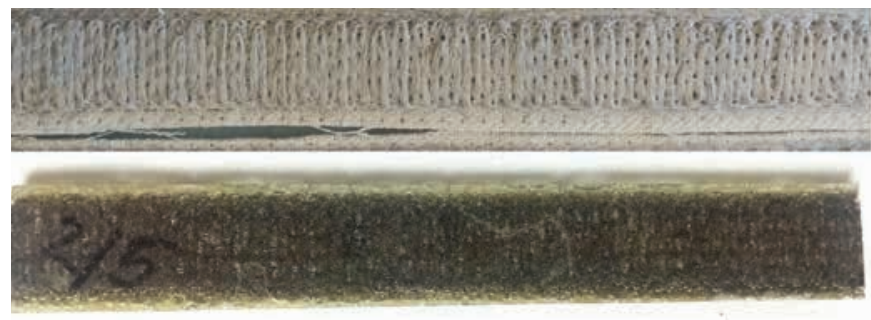

Figure 6. An example of an embroidery made (top) and a composite produced (bottom) - third variant of arrangement (own source). 
Figure 6 shows the embroidery and finished composites. Fiber volume ratio was $51 \%$.

\subsection{Methods}

The produced samples were then subjected to strength teststensile strength, tensile elongation, and bending strength.

The tensile strength and tensile elongation tests were carried out based on the PN-EN ISO 527-4 standard [20]. The test consisted of stretching the prepared samples with a constant speed until they break. During stretching, the values of relative elongation at maximum force, maximum force, breaking force, and relative elongation at break were recorded. The tests were conducted on a Shimadzu universal testing machine with a $50-\mathrm{kN}$ load cell. The velocity of the test was $1 \mathrm{~mm} /$ min. The elongation of the specimens was measured with the extensometer with a gauge length of $50 \mathrm{~mm}$.

The test's parameters are presented in Table 3.

Table 3. Parameters of tensile strength test and tensile elongation test

\begin{tabular}{|c|c|}
\hline Grips distance & $100 \mathrm{~mm}$ \\
\hline Speed of testing & $1 \mathrm{~mm} / \mathrm{min}$ \\
\hline Sample size & $190 \mathrm{~mm} \times 20 \mathrm{~mm} \times 5 \mathrm{~mm}$ \\
\hline Number of samples & 5 of each variant \\
\hline
\end{tabular}

Test results were given in the form of numerical data and a graph of tensile stress as a function of elongation.

The flexural properties were tested based on BS-EN ISO 14125: 1998 [21]. This test was performed according to the three-point bending test with the registration of the load. The test was carried out until the specimen was destroyed or the lower surface of the sample was in contact with the support. The test determined the maximum load and flexural stress.

Test parameters are presented in Table 4.

Table 4. Bending strength test's parameters

\begin{tabular}{|c|c|}
\hline Distance between supports & $80 \mathrm{~mm}$ \\
\hline Speed of testing & $5 \mathrm{~mm} / \mathrm{min}$ \\
\hline Sample size & $190 \mathrm{~mm} \times 20 \mathrm{~mm} \times 5 \mathrm{~mm}$ \\
\hline Number of samples & 5 of each variant \\
\hline
\end{tabular}

Both tests were carried out on the INSTRON 4485 universal testing machine at the Strength of Materials Laboratory, Faculty of Mechanical Engineering, Lodz University of Technology.

\section{Results and discussion}

\subsection{Tensile stress and tensile elongation}

Figure 7 shows the dependence of the tensile stress of individual variants on their elongation.

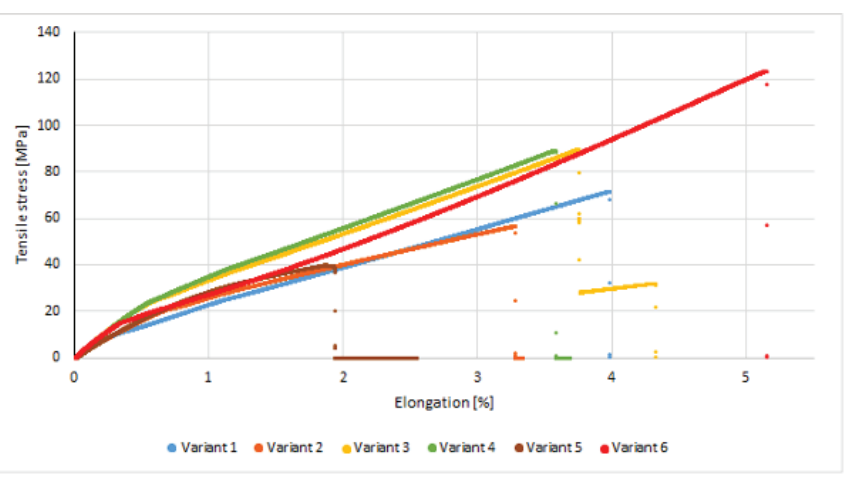

Figure 7. Stress and elongation of the produced composites.

With an elongation of about $0.3 \%$, we can notice a change in the slope of the graphs. This is a characteristic tensile feature of the composites. This indicates a crack in the first layer of the composite, reaching the so-called first-ply failure state, and thus irreversible changes will arise. Before this change, single, diffuse micro-cracks occurred, which do not cause any noticeable changes in the stretch plot. Only the accumulation of cracks violating the thickness of the composite above $0.1 \mathrm{~mm}$ leads to a change in the slope of the loading diagram [22].

Variant 6 showed the highest tensile strength. In this variant, the arrangement of the fibers in the embroidery was consistent with the action of the tensile force. The destruction of the sample took place when all fibers involved in stretching were completely ruptured. In the case of other variants, the maximum breaking load was lower. The fibers arranged at an angle to the tensile force were additionally affected by shear, bending, and breaking forces, which reduced the strength of the tested composites.

Values visible in the chart that were not included in the main set of values were registered after partial damage to the sample. After initial cracks appeared, the structure of the composite was not completely broken-individual sections of the roving and fibers were still intact and were broken when more force was applied. There was gradual delamination and accumulation of micro-cracks, eventually leading to the complete rupture of the sample.

Table 5 and Figure 8a, b show the average results of successive trials of individual variants along with the values of the standard deviation.

Variants 1, 3, and 4 showed similar elongation values, whereas option 2 showed a slightly lower elongation. Variant 5 had the smallest elongation-more than two times smaller than variant 6 . Variant 5 contained the most systems arranged at an angle of $90^{\circ}$, therefore, during stretching, these fibers were subject to shear forces. The high content of systems with an angle of $0^{\circ}$ (variants 3, 4, and 6) increased the elongation value.

Variants 3 and 4 showed similar tensile stress values; however, option 3 was characterized by higher stress. It contained more $0^{\circ}$ configurations, so in the stretching process more fibers transferred the stress. Variant 2 , which contained only one $0^{\circ}$ system less than the variant 1 , showed about $15 \%$ lower stress 
Table 5. The values of the mean elongation and the mean maximum stress of individual variants of reinforced composites together with the values of standard deviation

\begin{tabular}{|c|c|c|}
\hline Variant number & Mean elongation (\%) & Mean maximum tensile stress (MPa) \\
\hline 1 & $3.98 \pm 0.24$ & $71.5 \pm 3.9$ \\
\hline 2 & $3.31 \pm 0.02$ & $56.6 \pm 4.3$ \\
\hline 3 & $3.95 \pm 0.27$ & $93.4 \pm 7.9$ \\
\hline 4 & $3.85 \pm 0.30$ & $87.4 \pm 3.2$ \\
\hline 5 & $2.53 \pm 0.48$ & $39.2 \pm 6.8$ \\
\hline 6 & $5.30 \pm 0.14$ & $125.9 \pm 6.6$ \\
\hline
\end{tabular}
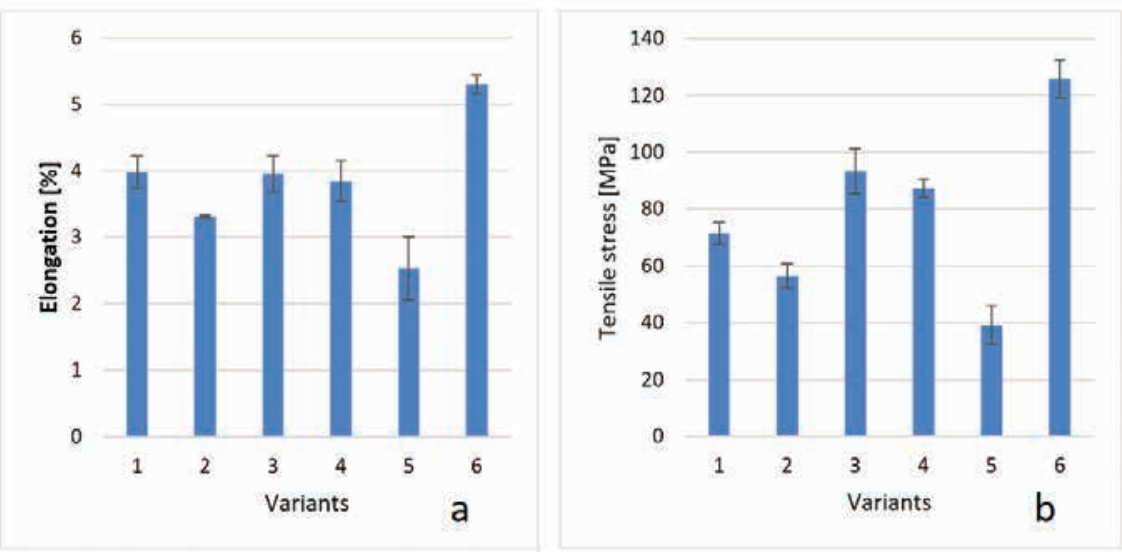

Figure 8. Average elongation (a) and tensile stress (b) of individual variants.

values than variant 1 . The lowest values of tensile stress were characteristics of variant 5 , which had the largest number of systems with an arrangement angle of $90^{\circ}$. The stress values of variant 5 were approximately two times lower than that of variants 1,3 , and 4 , and approximately $25 \%$ lower than that of variant 2 . Variant 5 contained twice as many systems with an angle of $90^{\circ}$ as variant 2 .

Based on the collected data, it can be clearly stated that variant 6 , which contained only the embroidery arranged at an angle of $0^{\circ}$ to the longitudinal direction of the sample, is characterized by the highest tensile stress and the highest elongation in unidirectional stretching. The stress values of this variant are over four times greater than that of variant 5 and about twice as high as the other variants.

In variant 6 , the tensile forces perform in the longitudinal direction of the sample, so the tensile forces also act along the fibers. In the case of $90^{\circ}$ layout, these forces act perpendicularly, so that fewer fibers are involved in the stretching process, and therefore these variants have lower strength. The same is true for $45^{\circ}$ systems where shear forces are also applied.

\subsection{Flexural properties}

Table 6 and Figure 9 show the average values of the successive tests of the produced composites during the three-point bending test.

Among the produced composites, variant 6 showed the highest flexural strength, at the maximum strength level of $141 \mathrm{MPa}$.

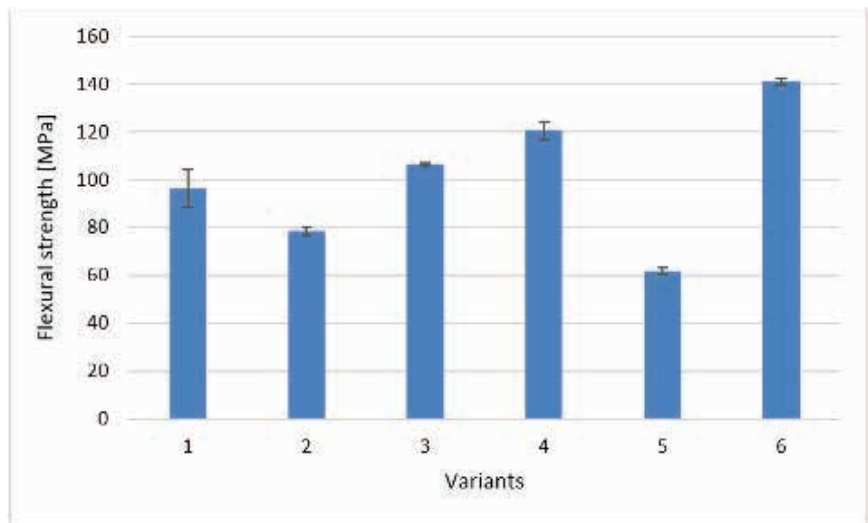

Figure 9. The average maximum flexural strength of composites during three-point bending tests.

Table 6. Values of the average flexural strength of the composite reinforced with embroidery

\begin{tabular}{|c|c|}
\hline Variant number & Mean flexural strength (MPa) \\
\hline 1 & $96.45 \pm 7.76$ \\
\hline 2 & $78.53 \pm 1.75$ \\
\hline 3 & $106.58 \pm 0.74$ \\
\hline 4 & $120.71 \pm 3.88$ \\
\hline 5 & $61.96 \pm 1.58$ \\
\hline 6 & $141.09 \pm 1.50$ \\
\hline
\end{tabular}


Variant 5 showed more than twice lower strength values than variant 6 .

Variant 4, which contained 4 layers with the direction of roving at $0^{\circ}$ angle, was also characterized by high flexural strengthapproximately $120 \mathrm{MPa}$. Variant 3, similar in structure to variant 4 , was slightly less durable. These variants ( 3 and 4 ) had the same number of $0^{\circ}$ layers (four), while the other layers differed from each other. Based on the comparison of these two variants, it can be concluded that the arrangement of the roving at an angle of $45^{\circ}$ has a more favorable effect on increasing the flexural strength than the $90^{\circ}$ angle of arrangement. When the roving is arranged in the $45^{\circ}$ direction, the fibers are subjected to bending, shear, and tensile forces. When the roving is arranged in the direction of $90^{\circ}$, the forces act perpendicular to the direction of the fibers, and the proportion of the fibers in the bending process is smaller. The difference in the maximum strength values achieved for these two variants is about $15 \%$.

Variants 1 and 2 contained the same $90^{\circ}, 45^{\circ}$, and $-45^{\circ}$ layers, but differed in the number of $0^{\circ}$ layers. Option 1 had two of them, while option 2 had one. Such a small difference in the number of layers with an angle of $0^{\circ}$ allowed to increase the strength by about $15 \%$.

As in the case of the tensile strength and tensile elongation tests, variants 2 and 5 had the lowest strength values.

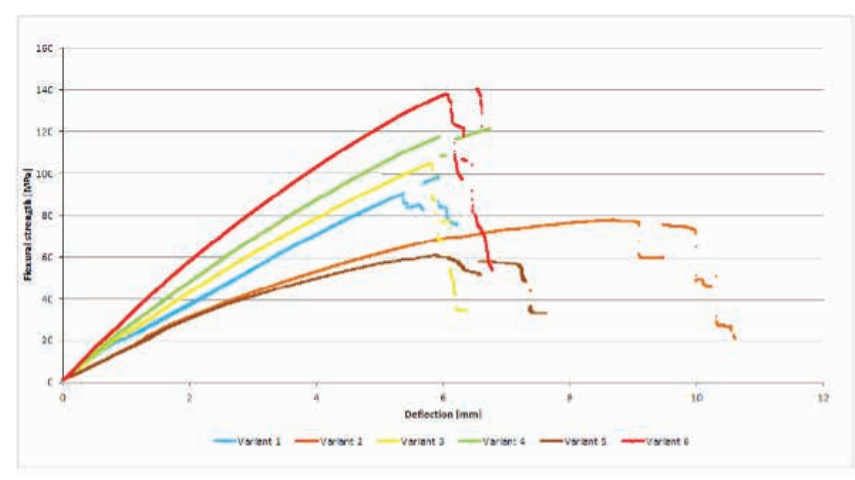

Figure 10. Flexural strength vs deflection of the manufactured variants.

All variants are characterized by a similar course of the plot lines. Single values that are not included in the main lines of the plot were recorded after the sample was partially damaged. The sample was incompletely destroyed — the individual fibers still remained unbroken, which made it possible to further record flexural strength.

Variant 6 was characterized by the highest flexural strength, with the largest number of systems with an arrangement angle of $0^{\circ}$. This is an analogous situation as for tensile strength.

Variants 2 and 5 are characterized by very similar graphs; however, variant 2 achieved a much greater deflection. The construction of these variants differs only in the use of one layer of roving at $0^{\circ}$ in variant 2 . This allowed for greater strength and a $50 \%$ greater deflection. Variant 5 did not contain any $0^{\circ}$ layer. The proportion of fibers arranged at an angle of $45^{\circ}$ reduces the stiffness of the composite and thus increases its deflection.
Variants 1,3 , and 4 showed successively higher strengths. Out of these, variant 1 contained the fewest layers with a $0^{\circ}$ arrangement-only two. Variants 3 and 4 contained four such layers-this confirms the conclusion that increasing the $0^{\circ}$ layers positively affects the composite strength improvement. In variant 3 , every second layer was placed at an angle of $90^{\circ}$, whereas in variant $4-$ at an angle of $45^{\circ}$ and $-45^{\circ}$. The reduced strength of the composite in the case of these two variants is due to the lower proportion of fibers in the bending process.

The values of the maximum deflection of all variants were similar and amounted to about $6 \mathrm{~mm}$. The only exception was variant 2 -its deflection was over $9 \mathrm{~mm}$. Layers with $45^{\circ}$ and $90^{\circ}$ roving angle reduce the value of composite stiffness. This can be seen from the lower slope of the curve in the graph. The more $45^{\circ}$ and $90^{\circ}$ layers the composite contained, the less stiffness it has-this can be especially observed in the case of variants 2 and 5 .

\section{Summary}

The study showed above presents results of strength tests of composites containing sevenfold embroidery systems with different directions of arrangement of individual layers as a reinforcement. Flax roving was used to strengthen the composite.

The mechanical properties of composites largely depend on the type of fibers used as reinforcement, the way they are arranged in the composite and their volume share. With the help of a computer embroidery machine, it is possible to control these parameters and give the produced material the expected properties.

In the experiment, a natural fiber, which is flax, was chosen to strengthen the composite, due to its high strength-the largest of all natural fibers.

Based on the experimental research carried out, the following conclusions were drawn.

1. The use of TFP technology for the production of composite reinforcement allows reducing material losses to a minimum. This process is possible, thanks to the use of a computerized embroidery machine. This machine allows for any programming of the arrangement of the medium forming the composite.

2. Most of the polymer composites are classified as brittle materials, and thus their relative elongation value ranges from $1 \%$ to $3 \%$ [23]. Among the variants produced, only variant 5 , containing the most systems with an angle of $90^{\circ}$, achieved an elongation below $3 \%$. The remaining variants oscillated around 4\%-the elongation of variant 6 was over $5 \%$. In fabrics, which are most often used to reinforce composites, the fibers do not run in a straight line-there are bends caused by the interweaving of weft and warp threads. This does not allow their mechanical properties to be fully exploited. In the case of embroidery, this thread 
deflection does not occur, so the fibers can bear the full load.

3. The combination of the systems with the roving angle of $90^{\circ}, 45^{\circ}$, and $-45^{\circ}$ (variant 5) showed the lowest values of tensile strength, elongation at tension, and flexural strength. This variant contained the most, as many as 4 , systems with an arrangement angle of $90^{\circ}$. Moreover, variant 2, which also comprised mainly $90^{\circ}, 45^{\circ}$, and $-45^{\circ}$ systems, exhibited low strength values as well. It can therefore be concluded that the arrangement of reinforcement fibers in the perpendicular and oblique direction to the action of the tensile and bending moment does not significantly improve the mechanical properties of a given composite. On the other hand, the arrangement of the roving, and hence the flax fibers, in the direction of the tensile force has a positive effect on increasing the tensile strength. This is due to the greater number of fibers involved in stretching along the force. However, when laying the fibers at an angle to the acting force, apart from the tensile force, also shear and flexural forces act, which additionally reduces the strength of the tested product.

4. The flexural test is one of the static methods of determining the strength properties of materials. With the increase in the share of layers with an angle of $0^{\circ}$, the flexural strength of the tested composites increased. It was caused by the increased proportion of fibers involved in the flexural process.

\section{Conclusions}

Based on the research, it can be clearly stated that the arrangement of the roving in the direction of the tensile force allowed obtaining the best mechanical properties. This is due to the anisotropic nature of the roving fibers. This fact should be taken into account when designing finished products containing embroidered patterns as reinforcement. In the case of beam systems, it is recommended to arrange the strengthening medium in the direction of the acting tensile forces. However, in the case of materials with similar longitudinal and transverse dimensions, it is recommended to use grid-shaped systems.

\section{Acknowledgments}

The ZSK embroidery machine type JCZA-0109 was purchased under the POWR.03.01.00-IP.08-00-DUO/18 project, cofinanced from the European Funds Knowledge Education Development.

\section{References}

[1] Michałowska, M. (2006). Leksykon włókienniczy; Krajowy Ośrodek Badań i Dokumentacji i Zabytków w Warszawie (Warszawa).

[2] Rajak, D. K., Pagar, D. D., Menezes, P. L., Linul, E. (2019). Fiber-reinforced polymer composites: Manufacturing, properties, and applications. Polymers, 11(10), 1667.
[3] Pecas, P., Carvalho, H., Salman, H., Leite, M. (2018). Natural fibre composites and their applications: A review. Journal of Composites Science, 2(4), 66.

[4] Raja, T., Anand, P., Karthik, M., Sundaraj, M. (2017). Evaluation of mechanical properties of natural fibre reinforced composites - a review. International Journal of Mechanical Engineering and Technology, 8(7), 915-924.

[5] Jauhari, N., Mishra, R., Thakur, H. (2015). Natural fibre reinforced composite laminates - A review. Materials Today: Proceedings, 2, 2868-2877.

[6] Lau, K., Hung, P., Zhu, M., Hui, D. (2018). Properties of natural fibre composites for structural engineering applications. Composites Part B: Engineering, 136, 222233.

[7] Czub, K., Barbursk, I. M. (2017). Mechanical properties of flax roving composites reinforcement. IOP Conference Series: Materials Science and Engineering, p. 254.

[8] Miedzianowska, J., Masłowski, M., Strzelec, K. (2018). The natural fiber reinforced polymer composites - factors affecting the mechanical performance. Technologia $i$ Jakość Wyrobów, 63, 45-54.

[9] Kamińska, A., Barbursk, I. M. (2018). 3D woven fabric with cross rib as a composite reinforcement. In IOP Conference Series: Materials Science and Engineering, Vol. 460, 18th World Textile Conference AUTEX 2018, Istanbul, Turkey.

[10] Yan, L., Chouw, N., Jayaraman, K. (2014). Flax fibre and its composites - A review. Composites: Part B, 56, 296-317.

[11] Vanleeuw, B., Carvelli, V., Lomov, S.V., Barburski, M., Vuure, A.W. (2014). Deformability of a flax reinforcement for composite materials. Key Engineering Materials, 611612, 257-264.

[12] Vanleeuw, B., Carvelli, V., Barburski, M., Lomov, S.V., van Vuure, A. W. (2015). Quasi-unidirectional flax composite reinforcement: deformability and complex shape forming. Composites Science and Technology, 110, 76-86.

[13] Lemmi, T., Barburski, M., Samuel, B. (2020). Analysis of mechanical properties of unidirectional flax fiber and satin woven fabric composite. Autex Research Journal, 1-6.

[14] Warrior, N. A., Rudd, C. D., Gardner, S. P. (1999). Experimental studies of embroidery for the local reinforcement of composites structures 1. Stress concentration. Composites Science and Technology, 59, 2125-2137.

[15] El-Dessoukya, H. M., Salehc, M. N., Gautamd, M., Hane, G., Scaifea, R. J., et al. (2019). Tailored fibre placement of commingled carbon-thermoplastic fibres for notchinsensitive composites. Composite Structures, 214, 348349.

[16] Poniecka, A., Barburski, M. (2020) Mechanical properties of technical embroidery made of flax fibers. In: Szłyk, E. (Ed.). Na pograniczu chemii, biologii i fizyki. Kopernikańskie Seminarium Doktoranckie, 1st ed. Wydawnictwo Naukowe Uniwersytetu Mikołaja Kopernika (Toruń), Vol. 1, pp. 303318.

[17] Mecnika, V., Hoerr, M., Krievins, I., Jockenhoevel, S., Gries, T. (2014). Technical embroidery for smart textiles: Review. Material Science. Textile and Clothing Technology, 9, 56-62.

[18] Gil, I., Fernandes-Garcia, R., Tornero, J. A. (2019). Embroidery manufacturing techniques for textile dipole antenna applied to wireless body area network. Textile Research Journal, 89(8), 1573-1581. 
[19] Tsolis, A., Whittow, W. G., Alexandridis, A. A., et al. (2014). Embroidery and related manufacturing techniques for wearable antennas: Challenges and opportunities. Electronics, 3, 314-338.

[20] PN-EN ISO 527-4:1997. Plastics - Determination of tensile properties - Part 4: Test conditions for isotropic and orthotropic fibre-reinforced plastic composites.

[21]BS EN ISO 14125:1998. Fibre-reinforced plastic composites - Determination of flexural properties.

[22] Bełzowski, A. (2007). Podstawowe wiadomości o próbach wytrzymałości materiałów kompozytowych. Retrieved July 30, 2020, Web site: http://www.wzwm.pwr.wroc.pl/files/ pages/inst_12.pdf.

[23] Boczkowska, A., Wojciechowski, S., et al. (2003). Kompozyty (2nd ed.). Oficyna Wydawnicza Politechniki Warszawskiej (Warsaw), p. 23. 